\title{
Changes in emotional-social intelligence, caring, leadership and moral judgment during health science education programs
}

\begin{abstract}
Hélène Larin ${ }^{1}$, Gerry Benson ${ }^{2}$, Jean Wessel ${ }^{3}$, Lynn Martin ${ }^{4}$, and Jenny Ploeg
Abstract: In addition to having academic knowledge and clinical skills, health care professionals need to be caring, ethical practitioners who are able to understand the emotional concerns of their patients and to effect change. The purpose of this study was to determine whether emotional-social intelligence, caring, leadership and moral judgment of health care students change from the beginning to the end of their programs. Students from nursing, bachelor of health science and two physical therapy programs completed self-report questionnaires to evaluate emotional-social intelligence [BarOn Emotional Quotient Inventory: Short (EQ-i:S)], caring [Caring Ability Inventory (CAI)] and leadership [SelfAssessment Leadership Inventory] at the beginning and end of their programs. Students in three of the programs also completed a test of moral decision-making [Defining Issues Test (DIT-2)] at both time points. Two-way analyses of variance (program versus time) demonstrated significant time effects for the total score of EQ-i:S, the Knowing subscale of CAI and the N2 score of the DIT-2. There were no other significant time effects and no major differences between programs. It can be concluded that health care and health science students show small improvements in emotional-social intelligence, caring, and moral judgment from the beginning to the end of their educational programs.
\end{abstract}

Keywords: emotional-social intelligence, caring, leadership, moral judgment, health science education

\section{Background and Purpose}

Educators in health care professional programs aim to develop specific attitudes and behaviors in their students, and teach them knowledge and skills relevant to their professions. Among the attitudes and behaviors desired in students and graduates of these programs are emotional-social intelligence (ESI), caring, leadership, and ethical behavior and decision making (American Physical Therapy Association, 2006; College of Nurses of Ontario, 2008; Physiotherapy Education Accreditation Canada, 2012). These attributes have been positively associated with clinical performance (Beauvais, Brady, O'Shea, \& Griffin, 2011; Rochester, Kilstoff, \& Scott, 2005; Sisola, 2000) as well as patients' outcomes (Palese et al., 2011). Educators would hope that the curricula of health care professional programs would contribute to enhancements in ESI, caring, leadership and moral judgment.

Bar-On (2002) defines ESI as "a multi-factorial array of emotional and social competencies that determine how effectively we relate with ourselves and others and cope with

\footnotetext{
${ }^{1}$ Ithaca College, Department of Physical Therapy, 953 Danby Road, Ithaca, NY 14850, hlarin@ithaca.edu

${ }^{2}$ McMaster University, School of Nursing, Hamilton, Ontario, Canada, bensong@mcmaster.ca

${ }^{3}$ McMaster University, School of Rehabilitation Science, Hamilton, Ontario, Canada, wesselj@mcmaster.ca

${ }^{4}$ McMaster University, School of Nursing, Hamilton, Ontario, Canada, martl@mcmaster.ca

${ }^{5}$ McMaster University, School of Nursing, Hamilton, Ontario, Canada, ploegj@mcmaster.ca
} 
daily demands and pressures" (p. 31). Various authors (Brewer \& Cadman, 2000; Gard \& Gyllensten, 2004; Rochester et al., 2005) have indicated that health professionals must understand their own and others' emotions so that they can use this knowledge to work with their colleagues, communicate effectively with their patients, deal with stress and uncertainty, and produce better treatment outcomes. Yet, research has not always demonstrated a positive change in the ESI of health science students over their programs. Lewis (2011) found no changes in the ESI of physical therapy students over a three-year program. Benson, Ploeg, and Brown (2010) showed that final-year nursing students had higher ESI than first-year students in a crosssectional study. However, in a subsequent longitudinal study (Benson, Martin, Ploeg, \& Wessel, 2012), nursing students had significant but small increases in only one subscale of ESI (adaptability). Larin et al. (2011) found no overall time effects when testing the ESI of nursing and physical therapy students at the beginning of their programs and after their first clinical placements.

'Caring' is an important concept in the health professions, (Romanello \& KnightAbowitz, 2000; Warelow \& Edward, 2007) and one that has been linked to ESI (Akerjordet \& Severinsson, 2008; Rego, Godinho, McQueen, \& Cunha, 2010; Wessel et al., 2008). Definitions of caring vary, but include reference to both the physical actions and emotional concern of the 'carer' as he/she supports and responds to the needs of others (McQueen, 2004). Caring has also been described as a relationship that involves receptivity, engrossment and reciprocity of the one caring and the person being cared for (Romanello \& Knight-Abowitz, 2000). Duffy (2005) pointed out that although 'caring' is integrated in nursing curricula, there is little information on the caring ability of nursing graduates. Significant increases in some aspects of caring have occurred in nursing students during and after their educational programs (Benson et al., 2012; Nelson, Howell, Larson, \& Karpiuk, 2001; Simmons \& Cavanaugh, 2000), but not in nursing and physical therapy students during the early parts of their programs (Larin et al., 2011).

Leadership ability is another attribute desired in health professionals (Borbasi \& Jackson, 2005; Snow, 2001). Jones and Sackett (2009) emphasized the need for leadership skills, not only in management and leadership positions, but also in everyday nursing practice. They suggested that leadership competencies at entry level to practice should include effective communication with healthcare professionals, translation of evidence into practice, and knowledge and skills related to information technology. Some studies in physical therapy (Lopopolo, Schafer, \& Nosse, 2004; Schafer, Lopopolo, \& Luedtke-Hoffmann, 2007) also identified communication as an important entry-level leadership skill, along with professional involvement, delegation and supervision, and ethical practice. Although Nelson et al. (2001) showed an increase in a leadership measure in nursing students from pre-clinical to the end of their program, other investigators failed to show significant changes for nursing or physical therapy students during their entry-level education programs (Benson et al., 2012; Larin et al., 2011).

Much has been written on the ethical practice/moral reasoning in the health professions (Barnitt, 1993; Barnitt, 1998; Barnitt \& Roberts, 2000; Sisola, 2000; Triezenberg, 1996; Triezenberg, 1997; Triezenberg \& Davis, 2000). Triezenberg and Davis (2000) contend that educators must go beyond the professional code of ethics and help students apply ethical theory to clinical situations, debate bioethics issues, and develop moral sensitivity (awareness of their own and others' values and beliefs). Longitudinal studies of health science students have shown mixed results; some showed no change (Dieruf, 2004; Kim, Park, Son, \& Han, 2004) while others showed improvements in moral judgment (Duckett et al., 1997; Geddes, Salvatori, \& Eva, 2009). 
In previous research, we studied these concepts in nursing, physical therapy and health science students at entry to their respective programs (Wessel et al., 2008). We found a relationship between ESI, caring and leadership, but not moral judgment. Students of different disciplines, levels of education (graduate or undergraduate) and instructional approach had similar scores on the measurement of these concepts. In order to determine the effect of professional curricula on these attributes, we decided to measure the changes that occurred in these students from entry to graduation. The three professional programs (1 nursing, 2 physical therapy) covered aspects of ESI, caring, leadership and moral judgment. The Bachelor of Health Science (BHSc) program did not specifically address any of them, other than ethics approval in research. The nursing curriculum was based on a 'caring' framework. One of the physical therapy programs followed a conventional educational method (lectures and laboratories) while the other three programs were problem-based (learning takes place in small tutorial groups and is based on case scenarios).

The purpose of this study was to determine if health professional students have an improvement in ESI, caring, leadership and moral judgment over the course of their programs. Based on the differences across programs, the following hypotheses were considered (also see Figure 1):

1. If the professional programs (academic and clinical) are the key to change, the nursing and physical therapy students will have greater changes in ESI, caring, leadership and moral judgment than the BHSc students in a non-professional program.

2. If disciplinary content makes a difference, the nursing students will have greater changes in caring than the other three groups.

3. If method of education is important, the students in the three problem-based programs will have greater changes in ESI, caring, leadership and moral judgment than the students in the conventional education program.

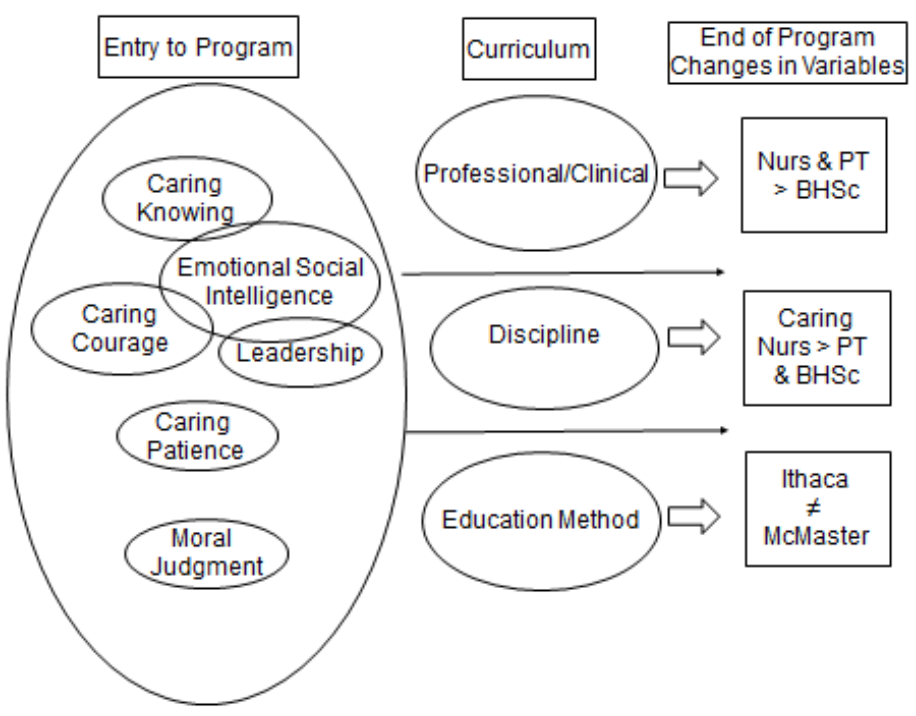

Figure 1. Conceptual framework demonstrating the relationship among ESI, caring, leadership and moral judgment at entry to program (left hand section) and the hypotheses for this study (remaining part of the figure). The hollow arrows represent specific hypotheses and the narrow arrows indicate expected changes due to curricula. 


\section{Methods}

\section{Study Design}

This study followed a pre-post, group comparison design.

\section{Participants and Settings}

Students from four programs and two educational institutions [McMaster University Bachelor of Health Science (BHSc), Nursing and Physical Therapy programs, and Ithaca College Physical Therapy program] were invited to participate in the study. Students in the BHSc and Nursing programs were in their first undergraduate year of their four-year programs. McMaster physical therapy students had completed varied undergraduate degrees and were commencing a 2-year (24 months) master's entry-level program. Ithaca students had completed 2 years of preprofessional, undergraduate studies, and were commencing 3 years of study that would lead to a master's entry-level degree in physical therapy. The inclusion of these cohorts allowed for the comparison of (a) professional programs versus a non-professional health science program (BHSc), (b) two health professional disciplines (physical therapy and nursing), and (c) two educational methods (problem-based learning and conventional). Although the groups were at different levels of education (undergraduate or graduate), we did not consider these comparisons because our previous work showed no differences in the study concepts of the four groups at baseline (Wessel et al., 2008). Sample size calculations indicated that 25 students per group were required to detect a between-group difference of one standard deviation (SD) on the EQ-i:S, with alpha $=0.05$, and power $=0.80$.

There were no specific curricular interventions targeting the outcome measures of ESI, caring, leadership and moral judgment in the four programs. However, the three professional programs addressed personal growth and client-centered approach, concepts similar to the personal and interpersonal aspects of ESI. Moreover, the students' clinical experiences were expected to increase their understanding and caring of others. The nursing curriculum was based on the caring concept of Bevis and Watson (2000) recognizing the need for students to have an awareness of self in order to engage in a professional caring relationship with patients. Leadership models were addressed in both the nursing program and the Ithaca physical therapy program, and the two physical therapy programs included content on ethical decision making.

Three of the cohorts (BHSc, nursing and McMaster physical therapy) received problembased education, where a health care problem/situation serves as the stimulus and guide to student learning in small group tutorials. As the students attempt to understand the problem, they identify their learning needs, research and apply information to the problem and work together as a group. These students were required to evaluate their own performance and that of others. Aspects of leadership, such as facilitating individuals, group process and task completion, were encouraged in the tutorial sessions. They learned their practical skills in laboratory sessions. Students in the Ithaca Physical Therapy program followed a conventional education method: content was provided in lectures, but small groups were utilized in the learning of practical skills. 


\section{Recruitment}

At entry to their respective programs, students were informed of the study via e-mail, and were asked to contact the research team if they were interested. All students who participated were asked to provide an email address so that they could be contacted in the last semester of their programs. A pizza lunch or a small gift certificate was provided to the participants at the end of each data collection session.

\section{Data Collection}

The study received ethical approval from the ethics review boards of both institutions involved in the study, and all participants provided written informed consent. All students completed a short demographic questionnaire and three self-report questionnaires: the BarOn Emotional Quotient Inventory Short (EQ-i:S) (Bar-On, 2006), the Caring Ability Inventory (CAI) (Nkongho, 2003), and the Self-Assessment Leadership Instrument (SALI) (Smola, 1988), on entry to their programs (Time 1), and in the final months of their programs (Time 2). Students in the BHSc and the two physical therapy programs also completed the Defining Issues Test (DIT-2) (Rest, Edwards, \& Thoma, 1997) at both time points. To decrease the burden of testing for the nursing students, they were not given the DIT-2 because they were completing another questionnaire as part of a larger study. The testing time was approximately 45-60 minutes. The lengths of time between the two data collection sessions were: 30, 42, 22, and 32 months for BHSc, Nursing, McMaster Physical Therapy and Ithaca Physical Therapy respectively.

\section{Measurement Tools}

The BarOn Emotional Quotient Inventory: Short (EQ-i:S) is a self-report measure of ESI behaviors (Bar-On, 2006). The EQ-i:S contains 51 statements which respondents rate on a scale ranging from 1 (very seldom or not true of me) to 5 (very often or true of me). A total score and five subscale scores (intrapersonal, interpersonal, stress management, adaptability and general mood) can be calculated. Raw scores are converted into standard scores based on age and gender. These normalized scores have a mean of 100 and SD of 15. A higher score indicates greater ESI, with Bar-On referring to standard scores of 85-115 as 'effective functioning', greater than 115 as 'enhanced skills', and less than 85 as 'area for enrichment'. Bar-On (2004) reported an internal consistency of 0.97 , and test retest reliability coefficients of 0.72 for males and 0.80 for females.

The Caring Ability Inventory (CAI) is a self-report measure that examines a person's ability to care for others (Nkongho, 2003). It is based on Mayeroff's (1971) definition of caring: "helping another grow and actualize himself ... a process, a way of relating to someone that involves development" (p. 1). The CAI consists of 37 items, each rated on a 7-point Likert scale ranging from 1 to 7 , and distributed across three subscales that were determined by factor analysis: Knowing [CAI_K] (14 items) relates to understanding of self and others, Courage [CAI_C] (13 items) captures ability to cope with the unknown, and Patience [CAI_P] (10 items) refers to tolerance and persistence. After reverse scoring of some items, the subscale scores are calculated by summing the items in that subscale. Higher scores indicate a greater degree of caring. The CAI is viewed as a reliable measure of caring with internal consistency on the total CAI ranging from 0.79 to 0.84 and a test retest coefficient of 0.75 (Nkongho, 2003). It has 
discriminated between nursing students and nurses, between nursing students and non-nursing students, and between females and males (Nkongho, 2003).

The Self-Assessment Leadership Inventory (SALI) is a measure of leadership characteristics, where leadership is defined as the process of influencing the behaviors of other persons in their efforts towards goal setting and achievement (Smola, 1988). This instrument was originally developed by Yura (1970) and incorporated various leadership theories. Respondents rate 40 behaviors as they relate to their leadership. A 5-point Likert scale is used indicating, "usually not behave in this manner" (0) to "almost always behave in this manner" (4). A higher total score indicates high self-assessment of leadership characteristics. Testing for internal consistency produced a Cohen's coefficient $\mathrm{K}$ of 0.54 . The SALI was able to discriminate between groups expected to be different on leadership ability (Smola, 1988).

The Defining Issues Test (DIT-2) is derived from Kohlberg's theory of the development of moral judgment, a process by which people determine one course of action is morally right and another course is morally wrong (Rest, Edwards, \& Thoma, 1997). The test consists of five ethical "dilemmas". For each dilemma, the respondents are asked to make a decision about the action to take and then rate 12 statements (on a 5-point scale) for their importance in making the decision. Finally they rank the 4 most important statements (Bebeau \& Thoma, 2003). A number of scores can be computer-generated. The N2 score was used in this study. It is a combined measure of ability to recognize principled items (ranking of these as most important) and to discard the simplistic and biased solutions (rate these lower than principled items). The construct validity has been supported by correlations between the N2 score and moral comprehension, prosocial behavior and civil libertarian attitudes, by differences in age/educational groups, and by longitudinal and interventional changes (Rest, Thoma, Narvaez, \& Bebeau, 1997). The BHSc and physical therapy students completed this questionnaire; the nursing students did not.

These tools are summarized in an appendix with definitions of the concepts and examples of items from each tool.

\section{Data Analysis}

The PASW statistical package, version 18 (SPSS Inc., 2009) was used for all analyses. The data were evaluated for fit with a normal distribution by means of the Kolmogorov-Smirnov statistic, with a Lilliefors significance level. As the $\mathrm{p}$ values for this test were $>0.05$ for all data, two-way analyses of variance (ANOVAs) with repeated measures were used to compare four groups on EQ-i:S, CAI and SALI scores, and three groups on the N2 score from the DIT-2 at Times 1 and 2. Effect sizes were estimated from the partial eta squared obtained from the ANOVA program. Significant program effects were further evaluated with a Tukey test. Alpha was set at $p<0.05$ for all tests.

\section{Results}

A baseline cohort of 157 students (BHSc 21, Nursing 76, McMaster Physical Therapy 21, Ithaca Physical Therapy 39) agreed to participate in the study. Of these, 132 students completed the questionnaires at Time 2. Dropouts were due to: withdrawing from program (Nursing 4, Ithaca Physical Therapy 3), delay in program (Nursing 6), and failure to respond to request to complete Time 2 questionnaires (BHSc 1, Nursing 11). The characteristics of the students completing the study are described in Table 1. 
Larin, H., Benson, G., Wessel, J., Martin, L., \& Ploeg, J.

Table 1

Characteristics of Participants

\begin{tabular}{lcccl}
\hline Program & N at T2 & Male/Female & $\begin{array}{c}\text { Age } \\
\text { mean (SD) }\end{array}$ & Educational Characteristics \\
\hline BHSc & 20 & $4 / 16$ & $18(0.5)$ & PBL, non-professional \\
& 205 & $84 / 121$ & 18 & \\
Nursing & 55 & $5 / 50$ & $20(4.0)$ & PBL, professional, caring \\
& 385 & $30 / 355$ & 20 & \\
McMaster PT & 21 & $1 / 20$ & $24(4.0)$ & PBL, professional \\
& 59 & $9 / 50$ & 25 & \\
Ithaca PT & 36 & $5 / 31$ & $20(2.1)$ & Conventional, professional \\
& 67 & $18 / 49$ & 21 & \\
Total & 132 & $15 / 117$ & $20.6(3.6)$ & \\
\hline
\end{tabular}

The numbers in italics are the values for the entire class from which the sample was drawn. BHSc: Bachelor of Health Science; PT: Physical Therapy; PBL: Problem-Based Learning.

The results of the EQ-i:S are presented in Figure 2, and the results of the CAI, SALI and N2 score in Table 2. The changes from Time 1 to Time 2 were not large in any of the measures; effect sizes ranged from 0.006 for CAI_P to 0.128 for the N2 score. Significant time differences were found for $\mathrm{EQ}-\mathrm{i}: \mathrm{S}$ total score $(\mathrm{F}=14.2, \mathrm{df}=1,128, p<0.001)$, CAI K $(\mathrm{F}=9.9, \mathrm{df}=1,126$, $p=0.002)$ and $\mathrm{N} 2$ score $(\mathrm{F}=10.9, \mathrm{df}=1,74, p=0.002)$. The only significant group by time interaction was found for the Stress Management subscale of the EQ-i:S $(\mathrm{F}=3.9, \mathrm{df}=3,128$, $p=0.010)$. The BHSc and McMaster physical therapy students had increases in their scores while nursing and Ithaca physical therapy students had minimal change. There were no significant group main effects for any of the measures.

\section{Discussion}

This is the first longitudinal study to measure the changes of ESI, caring, leadership and moral judgment concurrently in four cohorts representing different disciplines and educational approaches. The results showed small but significant improvements in measures of ESI, the knowing component of caring, and moral judgment. Except for a difference between the programs in the pattern of change in Stress Management (two groups had improved scores, two groups stayed the same), there were no differences between programs in any of the measures.

The results do not support any of the research hypotheses. The students in the professional programs did not have greater changes in ESI, caring, leadership and moral judgment than students in a non-professional program (BHSc). In spite of having a curriculum based on a caring framework, nursing students did not change more in this attribute than the physical therapy and BHSc students. In addition there were no differences in the changes occurring in students from the problem-based programs and the conventional education program. 


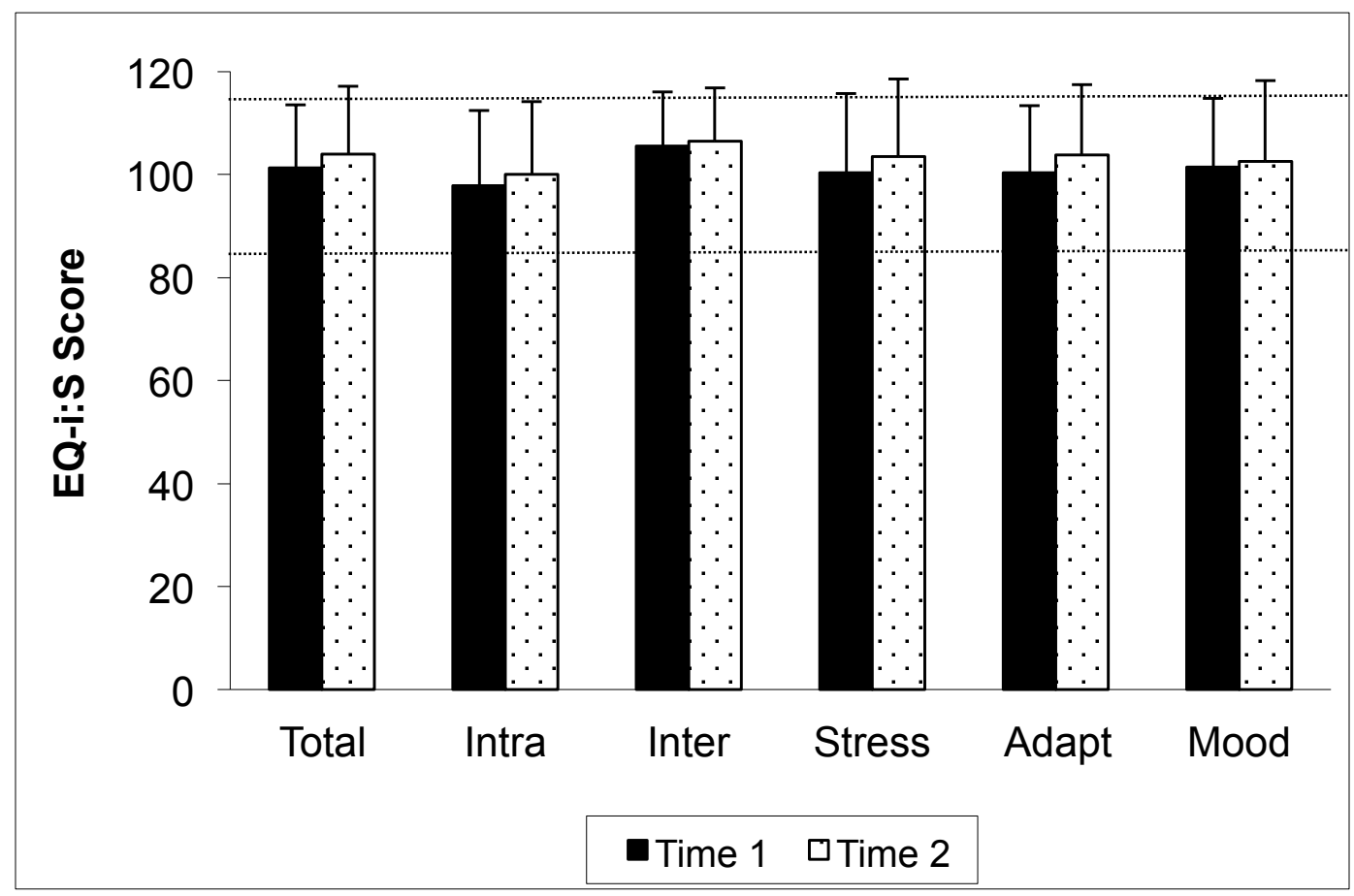

Figure 2. EQ-i:S standard scores (total and subscales) for all participants at beginning (Time 1) and end (Time 2) of their programs. The horizontal lines represent $\pm 1 \mathrm{SD}$ of the standard scores, and indicate 'effective functioning' of ESI. Subscales - Intra: Intrapersonal; Inter: Interpersonal; Stress: Stress Management; Adapt: Adaptability; Mood: General Mood.

Some results in this study are similar to previous work. Jaeger (2003) reported that graduate students in public administration programs had small but significant increases in total and subscale scores of the EQ-i:S following their participation in a general management course. Nelson et al. (2001) found an increase in SALI and CAI_K with little change in CAI_C for nursing students from preclinical to the end of their $\mathrm{BScN}$ program. However, they noted a decrease in CAI_P in their study while we found no change. The CAI_K includes awareness of self and others - two concepts that are noted in the Intrapersonal and Interpersonal subscales of EQ-i:S. An improvement in CAI_K may be due to the clinical and small group educational experiences of the students.

The mean values for the N2 score in the present study were above the means reported by Rest, Narvaez, Thoma, and Bebeau (1999) for college freshmen (30.6 \pm 14.4$)$, and college seniors $(40.4 \pm 13.6)$, but similar to scores they reported for students completing a professional degree $(45.0 \pm 14.9)$ or doctorate level education $(49.0 \pm 15.6)$. It is notable that there were no significant differences between the BHSc students and the students in the two physical therapy programs, because the BHSc students did not receive specific ethical training in their program. However, all programs required the students to evaluate information in making decisions.

Although the health care professional programs included many of the principles inherent in the concepts of ESI, caring, leadership and moral judgment, the participants did not show large changes in the measurement of these constructs. Perhaps very specific interventions are required to see major improvements. Graduate students receiving special ESI content in a general 
Larin, H., Benson, G., Wessel, J., Martin, L., \& Ploeg, J.

management course in a public administration program had greater changes in EQ-i:S (mean changes ranged from 6.6 to 9.90) than students who did not receive this content (mean changes ranged from 0.07 to 2.12) (Jaeger, 2003).

Table 2

Time 1 and Time 2 scores for measures of Emotional-Social Intelligence, Caring, Leadership and Moral Judgment

\begin{tabular}{lccccccc}
\hline Program & Time & $\begin{array}{c}\text { EQ-i:S } \\
\text { Total }\end{array}$ & CAI_K & CAI_C & CAI_P & SALI & $\begin{array}{c}\text { N2 } \\
\text { Score }\end{array}$ \\
\hline BHSc & 1 & 100.0 & 73.8 & 66.0 & 60.6 & 118.5 & 49.1 \\
N=20 & & $(12.6)$ & $(8.9)$ & $(6.7)$ & $(4.8)$ & $(16.1)$ & $(9.0)$ \\
& 2 & 106.0 & 79.5 & 66.8 & 60.7 & 120.5 & 52.1 \\
Nursing & 1 & $100.5)$ & $(8.3)$ & $(7.7)$ & $(4.3)$ & $(17.1)$ & $(9.9)$ \\
N=55 & & $(13.5)$ & $(9.2)$ & $(9.5)$ & $(5.6)$ & $(19.0)$ & \\
& 2 & 102.1 & 77.8 & 67.2 & 61.3 & 118.7 & \\
McMaster & 1 & $(14.5)$ & $(9.1)$ & $(8.7)$ & $(4.2)$ & $(16.9)$ & \\
PT N=21 & & $(11.5)$ & $(5.7)$ & $(8.9)$ & $(5.6)$ & $(13.8)$ & $(11.0)$ \\
& 2 & 103.5 & 80.8 & 66.9 & 62.2 & 123.8 & 51.8 \\
Ithaca & & $(15.2)$ & $(6.8)$ & $(10.4)$ & $(3.6)$ & $(15.1)$ & $(10.3)$ \\
PT N=36 & 1 & 104.9 & 79.1 & 68.1 & 61.8 & 121.4 & 43.5 \\
& & $(9.7)$ & $(5.4)$ & $(8.4)$ & $(4.2)$ & $(17.6)$ & $(13.9)$ \\
& 2 & 105.9 & 79.5 & 69.7 & 62.0 & 122.2 & 49.6 \\
Total & & $(11.0)$ & $(5.3$ & $(8.1)$ & $(3.3)$ & $(12.2)$ & $(12.5)$ \\
& 1 & $\mathbf{1 0 1 . 3}$ & $\mathbf{7 7 . 1}$ & 65.9 & 60.9 & 117.4 & $\mathbf{4 6 . 0}$ \\
& & $\mathbf{( 1 2 . 2 )}$ & $\mathbf{( 7 . 9 )}$ & $(8.8)$ & $(5.2)$ & $(17.6)$ & $\mathbf{( 1 2 . 1 )}$ \\
& 2 & $\mathbf{1 0 3 . 9}$ & $\mathbf{7 9 . 0}$ & 67.8 & 61.6 & 120.8 & $\mathbf{5 0 . 8}$ \\
& & $\mathbf{( 1 3 . 2 )}$ & $\mathbf{( 7 . 8 )}$ & $(8.7)$ & $(3.9)$ & $(15.4)$ & $\mathbf{( 1 1 . 3 )}$ \\
\hline
\end{tabular}

EQ-i:S: BarOn Emotional Quotient Inventory Short; CAI_K, CAI_C, CAI_P: Caring Ability Inventory Subscales Knowing, Courage and Patience respectively; SALI: Self-Assessment Leadership Instrument; N2 Score: from Defining Issues Test; PT: Physical Therapy.

Results in bold - significant $(\mathrm{p}<0.01)$ time effect from 2-way ANOVA (program versus time).

Perhaps there were only small changes in ESI because of the relatively high baseline values of the students. The mean total EQ-i:S score of 101.3 was higher than that recorded by Dawda and Hart (2000) for university students (mean 93.5) and by Suliman (2010) for second year nursing students (mean 86). However, the EQ-i:S in the present study was similar to that found for physicians (100.3) (Wagner, Moseley, Grant, Gore, \& Owens, 2002) and managers after a specific ESI intervention (100.8) (Slaski \& Cartwright, 2003). The mean EQ-i:S scores at all of the time points were within the 'effective functioning' range of ESI as defined by Bar-On (2002) (see Figure 2). The health professions likely attract persons with effective ESI, that is, persons interested in the welfare of others. Moreover, individuals that successfully compete for admission may have higher ESI than those not accepted to health professional programs. The 
BHSc students may also have had high ESI as the majority go on to apply to Medicine. In fact, higher scores in the total and three subscales of the EQ-i:S were correlated with higher cumulative grade point averages in first-year university students (Parker, Duffy, Wood, Bond, \& Hogan, 2005).

If students are currently in an 'effective functioning' range, is there any advantage to increasing their EQ-i:S score to the enhanced functioning level? Bar-On (2002) has indicated that individuals with 'enhanced' ESI are exceptionally effective, both emotionally and socially, in all aspects of their lives, and are usually successful in achieving their goals. Although ESI of nurses and nursing students has been correlated with their clinical performance (Beauvais et al., 2011; Codier, Kooker, \& Schoultz, 2008; Morrison, 2008), no studies have examined the added value of obtaining 'enhanced' ESI skills. It is possible that ESI will change more with work experience than with entry-level education. More research is required to identify what level of ESI is needed for effective practice, and whether specific educational experiences can enhance ESI.

There are limitations to our study related to the sample. Only $18.4 \%$ of the total cohort of students entered and completed the study, and all students were volunteers. The number of participants was slightly less than the sample size calculations required for the BHSc and McMaster physical therapy students. Thus the sample may not be representative of the majority of students in the programs. However, the inclusion of two higher education institutions, two health disciplines, and a non-professional program should increase the generalizability of our results. It is unlikely that a larger sample size would have provided more significant results because the effect sizes, as estimated by the partial eta squared from the ANOVA, were very small.

The measures used in this study will also affect the results. Three of the measures were self-report questionnaires, and thus only reflect the individuals' view of their own ESI, leadership and caring. The DIT-2, on the other hand, was a test that evaluates the students' ability in moral judgment and was not administered to nursing students. Results could be different if we used instruments that involved observation of behavior or opinions of others such as instructors, peers or clients. While the EQ-i:S tool is normalized for different age groups, the other measures are not. It is possible that age might make a difference to the scores for caring, leadership and moral judgment. On the other hand, there were no differences among groups at baseline, though the McMaster physical therapy students were older than the other cohorts.

This study was designed to examine the effects of different curricula on ESI, caring, leadership and moral judgment. Small changes occurred in three of these attributes, but we were unable to determine what curricular characteristics contributed to the changes because results were similar across the four student cohorts. Educators have a responsibility to prepare health care professional students for the emotional and social demands of their roles. Therefore, further research is needed to determine the optimal levels of ESI, caring, leadership and moral judgment required for effective health care practice. Then, educators need to examine specific educational strategies for their ability to help students develop their skills in these areas.

\section{Conclusion}

Health science students had small improvements in ESI, caring and moral judgment from the beginning to the end of their programs. The changes were similar in students from 
professional and non-professional health science programs, in nursing and physical therapy disciplines, and in students from problem-based and conventional educational programs.

\section{Acknowledgements}

The authors wish to thank the students of the Bachelor of Health Science, Nursing and Physical Therapy programs for their voluntary participation in the study, and those students who worked on this study as part of their research practicum. This project was supported by a grant from the McMaster Nursing Education Research Unit and two grants from Ithaca College (Seed Research Fund, School of Health Sciences and Human Performance; Small Grant for Faculty Research, Office of the Provost).

\section{Appendix}

Appendix 1. Outline of tools to measure emotional-social intelligence, caring, leadership and moral judgment.

\begin{tabular}{|c|c|c|c|}
\hline Concept & Measurement Tool & Definition & $\begin{array}{l}\text { Sample Items from } \\
\text { Measurement Tool }\end{array}$ \\
\hline $\begin{array}{l}\text { Emotional-Social } \\
\text { Intelligence (ESI) }\end{array}$ & $\begin{array}{l}\text { BarOn Emotional } \\
\text { Quotient Inventory: Short } \\
\text { (EQ-i:S) }\end{array}$ & $\begin{array}{l}\text { "a multi-factorial array of } \\
\text { emotional and social } \\
\text { competencies that determine } \\
\text { how effectively we relate } \\
\text { with ourselves and other and } \\
\text { cope with daily demands and } \\
\text { pressures" (Bar-On, 2002) }\end{array}$ & $\begin{array}{l}\text { I believe in my ability to handle } \\
\text { most upsetting problems. } \\
\text { In handling situations that } \\
\text { arise, I try to think of as many } \\
\text { approaches as I can. }\end{array}$ \\
\hline \multirow[t]{4}{*}{ Caring } & \multirow[t]{4}{*}{$\begin{array}{l}\text { Caring Ability Inventory } \\
\text { (CAI) }\end{array}$} & $\begin{array}{l}\text { Ability of a person to care for } \\
\text { others (Nkongho, 2003) }\end{array}$ & \\
\hline & & $\begin{array}{l}\text { Caring: Knowing } \\
\text { (understanding of self and } \\
\text { others) }\end{array}$ & $\begin{array}{l}\text { When I care for someone else, I } \\
\text { do not have to hide my feelings. } \\
\text { I accept people just the way } \\
\text { they are. }\end{array}$ \\
\hline & & $\begin{array}{l}\text { Caring: Courage } \\
\text { (ability to cope with the } \\
\text { unknown) }\end{array}$ & $\begin{array}{l}\text { I feel uneasy knowing that } \\
\text { another person depends on me. } \\
\text { There is very little I can do for } \\
\text { a person who is helpless }\end{array}$ \\
\hline & & $\begin{array}{l}\text { Caring: Patience } \\
\text { (tolerance and persistence) }\end{array}$ & $\begin{array}{l}\text { I believe that learning takes } \\
\text { time. } \\
\text { I admire people who are clam, } \\
\text { composed and patient. }\end{array}$ \\
\hline Leadership & $\begin{array}{l}\text { Self-Assessment } \\
\text { Leadership Inventory } \\
\text { (SALI) }\end{array}$ & $\begin{array}{l}\text { Process of influencing the } \\
\text { behaviors of other persons in } \\
\text { their efforts towards goal } \\
\text { setting and achievement } \\
\text { (Smola, 1988) }\end{array}$ & $\begin{array}{l}\text { Have group members share in } \\
\text { the decision making. } \\
\text { Alter your own behavior in } \\
\text { order to meet a situation. }\end{array}$ \\
\hline $\begin{array}{l}\text { Moral Judgment } \\
\text { (MJ) }\end{array}$ & $\begin{array}{l}\text { Defining Issues Test } \\
\text { (DIT-2) }\end{array}$ & $\begin{array}{l}\text { Process by which people } \\
\text { determine one course of } \\
\text { action is morally right and } \\
\text { another course is morally } \\
\text { wrong (Rest, Edwards, \& } \\
\text { Thoma, 1997) }\end{array}$ & $\begin{array}{l}\text { Respondent rates the } \\
\text { importance of statements } \\
\text { related to decision making } \\
\text { about social dilemmas } \\
\text { described in scenarios. }\end{array}$ \\
\hline
\end{tabular}




\section{References}

Akerjordet, K., \& Severinsson, E. (2008). Emotionally intelligent nurse leadership: A literature review study. Journal of Nursing Management, 16(5), 565-577. doi: 10.1111/j.13652834.2008.00893.x

American Physical Therapy Association (APTA) (2006). Evaluative Criteria for Accreditation of Education Programs for the Preparation of Physical Therapists. Retrieved from http://www.capteonline.org/uploadedFiles/CAPTEorg/About_CAPTE/Resources/Accreditation Handbook/EvaluativeCriteria_PT.pdf.

Barnitt, R. E. (1993). 'Deeply troubling questions': The teaching of ethics in undergraduate courses. British Journal of Occupational Therapy, 56, 401-406.

Barnitt, R. E. (1998). Ethical dilemmas in occupational therapy and physical therapy: A survey of practitioners in the UK National Health Service. Journal of Medical Ethics, 24, 193-199. doi: 10.1136/jme.24.3.193

Barnitt, R. E., \& Roberts, L. C. (2000). Facilitating ethical reasoning in student physical therapists. Journal of Physical Therapy Education, 14(3), 35-41.

Bar-On, R. (2002). BarOn emotional quotient inventory: Short (EQ-i:S): Technical manual. Toronto, ON: Multi-Health Systems Inc.

Bar-On, R. (2004). The Bar-On emotional quotient inventory (EQi): Rationale, description, and summary of psychometric properties. In G. Geher (Ed.), Measuring emotional intelligence: Common ground and controversy (pp. 111-142). Hauppauge, NY: Nova Science Publishers.

Bar-On, R. (2006). The Bar-On model of emotional-social intelligence (ESI). Psicothema, 18(Supp.), 13-25.

Beauvais, A. M., Brady, N., O'Shea, E. R., \& Griffin, M. T. (2011). Emotional intelligence and nursing performance among nursing students. Nurse Education Today, 31(4), 396-401. doi: 10.1016/j.nedt.2010.07.013

Bebeau, M. J., \& Thoma, S. J. (2003). Guide for DIT-2. Minneapolis, MN: University of Minnesota.

Benson, G., Ploeg, J., \& Brown, B. (2010). A cross-sectional study of emotional intelligence in baccalaureate nursing students. Nurse Education Today, 30, 49-53. doi:

10.1016/j.nedt.2009.06.006

Benson, G., Martin, L., Ploeg, J. \& Wessel, J. (2012). Longitudinal study of emotional intelligence, leadership, and caring, in undergraduate nursing students. Journal of Nursing Education, 51(2), 95-101. doi: 10.3928/01484834-20120113-01 
Larin, H., Benson, G., Wessel, J., Martin, L., \& Ploeg, J.

Bevis, E. O., \& Watson, J. (2000). Toward a caring curriculum: A new pedagogy for nursing. Sudbury, MA: Jones and Bartlett Publishers.

Borbasi, S., \& Jackson, D. (2005). Nursing leadership: Power, politics and gender: The role of emotional intelligence. Collegian, 12(1), 5-6. doi: 10.1016/S1322-7696(08)60475-8

Brewer, J., \& Cadman, C. (2000). Emotional intelligence, enhancing student effectiveness and patient outcomes. Nurse Educator, 25(6), 264-266. doi: 10.1097/00006223-200011000-00006

Codier, E., Kooker, B. M., \& Schoultz, J. (2008). Measuring the emotional intelligence of clinical staff nurses. An approach for improving the clinical care environment. Nursing Administration Quarterly, 32(1), 8-14. Doi: 10.1097/01.NAQ.0000305942.38816.3b

College of Nurses of Ontario (CNO). (2008). National competencies in the context of entry-level registered nurse practice. Toronto, ON: CNO. Retrieved from http://www.cno.org/docs/reg/41037 EntryToPracitic final.pdf.

Dawda, D., \& Hart, S. D. (2000) Assessing emotional intelligence: reliability and validity of the Bar-On Emotional Quotient Inventory (EQ-i) in university students. Personality and Individual Differences, 28, 797-812. doi: 10.1016/S0191-8869(99)00139-7

Dieruf, K. (2004). Ethical decision-making by students in physical and occupational therapy. Journal of Allied Health, 33(1), 24-30.

Duckett, L., Rowan, M., Ryden, M., Krichbaum, K., Miller, M., Wainwright, H., \& Savik, K. (1997). Progress in the moral reasoning of baccalaureate nursing students between program entry and exit. Nursing Research, 46(4), 222-229. doi: 10.1097/00006199-199707000-00007

Duffy, J. R. (2005). Want to graduate nurses who care? Assessing nursing students' caring competencies. Annual Review of Nursing Education, 3, 59-76.

Gard, G., \& Gyllensten, A. L. (2004). Are emotions important for good interaction in treatment situations? Physiotherapy Theory and Practice, 20, 107-119. doi: 10.1080/09593980490452995

Geddes, E. L., Salvatori, P., \& Eva, K. W. (2009). Does moral judgement improve in occupational therapy and physiotherapy students over the course of their pre-licensure training? Learning in Health and Social Care, 8(2), 92-102. doi: 10.1111/j.1473-6861.2008.00205.x

Jaeger, A. J. (2003). Job competencies and the curriculum: An inquiry into emotional intelligence in graduate professional education. Research in Higher Education, 44(6), 615-639. doi: 10.1023/A:1026119724265

Jones, J. M., \& Sackett, K. (2009). Integrating leadership and management content across the curriculum: A 3-course approach. Nurse Educator, 34(5), 204-208. doi: 10.1097/NNE.0b013e3181b4c4c6 
Larin, H., Benson, G., Wessel, J., Martin, L., \& Ploeg, J.

Kim, Y. S., Park, J. W., Son, Y. J., \& Han, S. S. (2004). A longitudinal study on the development of moral judgement in Korean nursing students. Nursing Ethics, 14, 309-319.

Larin, H. M., Benson, G., Martin, L., Wessel, J., Williams, R., \& Ploeg, J. (2011). Examining change in emotional-social intelligence, caring, and leadership in health professions students. Journal of Allied Health, 40(2), 96-102.

Lewis, E. (2011). Longitudinal assessment of emotional intelligence in Doctor of Physical Therapy students. The Internet Journal of Allied Health Sciences and Practice, 9(2).

Lopopolo, R. B., Schafer, D. S., \& Nosse, L. J. (2004). Leadership, administration, management, and professionalism (LAMP) in physical therapy: A Delphi study. Physical Therapy, 84(2), 137150.

Mayeroff, M. (1971). On caring. New York, NY: Harper \& Row.

McQueen, A. C. (2004). Emotional intelligence in nursing work. Journal of Advanced Nursing, 47(1), 101-108. doi: 10.1111/j.1365-2648.2004.03069.x

Morrison, J. (2008). The relationship between emotional intelligence competencies and preferred conflict-handling styles. Journal of Nursing Management, 16, 974-983. doi: 10.1111/j.13652834.2008.00876.x

Nelson, M. L., Howell, J. K., Larson, J. C., \& Karpiuk, K. L. (2001). Student outcomes of the healing web: Evaluation of a transformative model for nursing education. Journal of Nursing Education, 40(9), 404-413.

Nkongho, N. O. (2003). The caring ability inventory. In O. L. Strickland, \& C. Dilorio (Eds.), Measurement of nursing outcomes, volume 3: Self care and coping (pp. 184-198). New York, NY: Springer Publishing.

Palese, A., Tomietto, M., Suhonen, R., Efstathiou, G., Tsangari, H., Merkouris, A., Papastavrou, E. (2011). Surgical patient satisfaction as an outcome of nurses' caring behaviors: A descriptive and correlational study in six European countries. Journal of Nursing Scholarship, 43(4), 341350. doi: 10.1111/j.1547-5069.2011.01413.x

Parker, J.D.A., Duffy, J.M., Wood, L.M., Bond, B.J., \& Hogan, M.J. (2005). Academic achievement and emotional intelligence: Predicting the successful transition from high school to university. Journal of the First-Year Experience and Students in Transition, 17(1), 67-78.

Physiotherapy Education Accreditation Canada (PEAC). (2012). 2012 Accreditation standards for physiotherapy education programs in Canada. London, ON: PEAC. Retrieved from: http://www.peacaepc.ca/PDFs/Accreditation\%20Standards/FINALPEACSTANDARDS2012_000.pdf 
Larin, H., Benson, G., Wessel, J., Martin, L., \& Ploeg, J.

Rego, A., Godinho, L., McQueen, A., \& Cunha, M. P. (2010). Emotional intelligence and caring behaviour in nursing. Service Industries Journal, 30(9), 1419-1437. doi:

$10.1080 / 02642060802621486$

Rest, J., Edwards, L., \& Thoma, S. (1997). Designing and validating a measure of moral judgment: Stage preference and stage consistency approaches. Journal of Educational Psychology, 89(1), 5-28. doi: 10.1037/0022-0663.89.1.5

Rest, J., Thoma, S. J., Narvaez, D., \& Bebeau, M. J. (1997). Alchemy and beyond: Indexing the defining issues test. Journal of Educational Psychology, 89(3), 498-507. doi: 10.1037/00220663.89.3.498

Rest, J. R., Narvaez, D., Thoma, S. J., \& Bebeau, M. J. (1999). DIT2: Devising and testing a revised instrument of moral judgment. Journal of Educational Psychology, 91(4), 644-659. doi: 10.1037/0022-0663.91.4.644

Rochester, S., Kilstoff, K., \& Scott, G. (2005). Learning from success: Improving undergraduate education through understanding the capabilities of successful nurse graduates. Nurse Education Today, 25(3), 181-188. doi: 10.1016/j.nedt.2004.12.002

Romanello, M., \& Knight-Abowitz, K. (2000). The "ethic of care" in physical therapy practice and education: Challenges and opportunities. Journal of Physical Therapy Education, 14(3), 2025 .

Schafer, D. S., Lopopolo, R. B., \& Luedtke-Hoffmann, K. A. (2007). Administration and management skills needed by physical therapist graduates in 2010: A national survey. Physical Therapy, 87(3), 261-281. doi: 10.2522/ptj.20060003

Simmons, P., \& Cavanaugh, S. (2000). Relationships among student and graduate caring ability and professional school climate. Journal of Professional Nursing, 16(2), 76-83. doi: 10.1016/S8755-7223(00)80019-8

Sisola, S. W. (2000). Moral reasoning as a predictor of clinical practice: The development of physical therapy students across the professional curriculum. Journal of Physical Therapy Education, 14(3), 26-34.

Slaski, M., \& Cartwright, S. (2003). Emotional intelligence training and its implications for stress, health and performance. Stress and Health, 19, 233-239. doi: 10.1002/smi.979

Smola, B. K. (1988). Refinement and validation of a tool measuring leadership characteristics of baccalaureate nursing students. In C. F. Waltz, \& O. L. Strickland (Eds.), Measurement of nursing outcome, volume two: Measuring nursing performance: Practice, education and research (pp. 314-336). New York, NY: Springer Publishing.

Snow, J. L. (2001). Looking beyond nursing for clues to effective leadership. Journal of Nursing Administration, 31(9), 440-443. doi: 10.1097/00005110-200109000-00010 
Larin, H., Benson, G., Wessel, J., Martin, L., \& Ploeg, J.

SPSS Inc. (2009). PASW statistics for windows. Chicago, IL: SPSS Inc.

Suliman, W. A. (2010). The relationship between learning styles, emotional social intelligence, and academic success of undergraduate nursing students. Journal of Nursing Research, 18(2), 136-143.

Triezenberg, H. L. (1996). The identification of ethical issues in physical therapy practice. Physical Therapy, 76(10), 1097-1107.

Triezenberg, H. L. (1997). Teaching ethics in physical therapy education: A Delphi study. Journal of Physical Therapy Education, 11(2), 16-22.

Triezenberg, H. L., \& Davis, C. M. (2000). Beyond the code of ethics: Educating physical therapists for their role as moral agents. Journal of Physical Therapy Education, 14(3), 48-58.

Wagner, P. J., Moseley, G. C., Grant, M. M., Gore, J. R., \& Owens, C. (2002). Physicians' emotional intelligence and patient satisfaction. Family Medicine, 34(10), 750-754.

Warelow, P., \& Edward, K. (2007). Caring as a resilient practice in mental health nursing. International Journal of Mental Health Nursing, 16, 132-135. doi: 10.1111/j.14470349.2007.00456.x

Wessel, J., Larin, H., Benson, G., Brown, B., Ploeg, J., Williams, R., \& Martin, L. (2008). Emotional-social intelligence in health science students and its relation to leadership, caring and moral judgment. The Internet Journal of Allied Health Sciences and Practice, 6(1).

Yura, H. (1970). Faculty perceptions of behavior indicating leadership potential of baccalaureate nursing students. Washington, DC: Catholic University of America. 